\title{
QUESTIONING THE VALIDITY, VERACITY AND VIABILITY OF THE CASE FOR “COGNO-NORMATIVE (COMPLEMENTARY) EPISTEMOLOGY”: A CONVERSATION WITH CHIMAKONAM \\ DOI: http://dx.doi.org/10.4314/ft.v5i1.8
}

\author{
Victor C. A. NWEKE, csp \\ Department of Philosophy, University of Calabar
}

\begin{abstract}
In this short conversation, I will engage Jonathan Chimakonam's essay entitled "The knowledge Question in African Philosophy: A Case for Cogno-Normative (Complementary) Epistemology" published as the chapter four of [Atuolu Omalu: Some Unanswered Questions in Contemporary African Philosophy]. I will identify the major submissions of the essay and engage them critically with the aim of opening new vistas of thought. My method will be conversationalim.
\end{abstract}

Keywords: Conversational philosophy, Jonathan Chimakonam, African philosophy, epistemology, cogno-normative

\section{Introduction}

One of the presumed "unanswered questions" addressed in the book, [Atuolu Omalu: Some Unanswered Questions in Contemporary African Philosophy], edited by Jonathan Chimakonam is the epistemological question. The essay that addressed the said question is titled "The knowledge Question in African Philosophy: A Case for Cogno-Normative (Complementary) Epistemology" and was written by Jonathan O. Chimakonam (2015a, 67-81). As a strong advocate of the thesis of the Conversational School of Philosophy (CSP) on the indispensability of incessant critical but creative interrogation, repudiation, emendation and reconstruction of existing propositions in African philosophy by seasoned and budding African philosophers to the systematic development of African philosophy as an academic discipline, I shall in this essay subject the propositions of Chimakonam's essay to the crucial test of Conversational Philosophy.

Accordingly, I shall succinctly present what I consider to be Chimakonam's basic arguments (2015a) for "Cogno-Normative (Complementary) Epistemology" (CE) and its nature and then proceed to examine the validity, veracity and viability of $\mathrm{CE}$ as an epistemological doctrine in African philosophy. In doing this, I shall draw attention towards a rigorous reconceptualization and systematic development of $\mathrm{CE}$ as a viable epistemological theory that can meaningfully engage and complement רepistemological theories articulated in other philosophical traditions in the global arena of intercultural/comparative philosophy.

OOn the Arguments for Cogno-Normative (Complementary) Epistemology $\approx$ Chimakonam's basic arguments for the construction of CE can be lucidly summarized as follows: 
A1: Knowledge is indispensable for the survival of the human species in the world. "The environment and quality of life of a people..." as well as the "ambitions of a society bear witness to the quality of knowledge they possess and the ones they pursue." Precolonial Africa was "far behind Europe in terms of environment, quality of life and ambition." Therefore, the European colonialists that came to colonize Africa were from a society that possessed a more sophisticated knowledge than Africa (2015, 67-8).

A2: A sophisticated knowledge is a product of the creative and innovational thoughts of individuals. The prevailing natural and socio-economic circumstance within a given society is what propels individuals towards creative and innovational thoughts. The "early inhabitants of Europe were predisposed to develop and possess a more sophisticated knowledge through creative and innovative thinking because of their unfriendly circumstances (in contrast to Africa, "Europe is a continent profusely disposed to all sorts of natural disasters" and "sparingly endowed with nature's resources"). Therefore, "the current consternation and challenges like poverty, conflicts, diseases and general disquiet which has continued to grow in post-colonial Africa would in no less a way constitute similar lunch-pads for creative and innovative thinking in Africa" (68).

A3: Individuals "cherish glory above everything else." Serious commitments to the production of a sophisticated knowledge is more pronounced in a society where individuals are "celebrated and readily recognized" for their creative and innovational thoughts. The nature of "Africa's communitarian ontology" does not create room for the meaningful recognition of individuals that achieve "great feats especially those that have to do with art, craft and intellect" and the absence of such recognition does not inspire individuals to be committed to the enterprise of creative and innovational thinking in pristine Africa. Therefore, the aspects of Africa's communitarian ontology that neglect the creative and innovational thoughts of individuals must be eliminated to encourage the articulate construction of a sophisticated "African episteme" (68-9).

A4: "In philosophy as in civilization, science and technology, Western episteme is arguably better articulated than that of African thought" but the Eurocentric claim that pristine Africans are inherently incapable of constructing any episteme that is qualitatively similar to the Western episteme is erroneous. The Eurocentric claim raises the knowledge question in African philosophy and addressing this question calls for the construction of a sophisticated knowledge that can "solve nagging African problems" using "the logical structures of African thought, excluding the spiritual perspective." Existing responses to the knowledge question in African 
philosophy are mainly either ethnocentric or metaphilosophical polemics that amounts to perverse dialogues. Therefore, the challenge of constructing an articulate and rigorous African episteme that is qualitatively as useful and sophisticated as the Western episteme is yet to be met. CE in an attempt to fill this lacuna (69-75).

\section{On the Nature of Cogno-Normative (Complementary) Epistemology}

The major tenets that define the nature of CE as articulated by Chimakonam (2015a) can be summarized with the following propositions:

P1: CE is an articulate epistemological theory "for African philosophy" (69).

P2: $\quad$ CE addresses "the knowledge question in African philosophy by (1) investigating what it means 'to know' in a modern Africa that is facing numerous challenges (2) the connection between the rational and the empirical modes of knowing and (3) the connection between knowledge, morality and community" (69).

P3: $\quad$ CE adapts the logical structure, and the normative and complementary principles of knowledge inherent in African thought but it jettisons the aspects of Africa's communitarian ontology that projects communal thoughts rather than the creative and innovational thoughts of individuals because a viable African episteme that can address the current challenges in Africa must: have "positive moral content" and can only be constructed by the creative and innovational thoughts of individual scholars from the African thought system through the complementary fusion of both the rational and empirical modes of knowing (73-4, 79-81).

\section{On the Validity and Veracity of CE}

Every philosophical theory is made up of arguments and the first basic feature of a rigorous philosophical theory is that its arguments must be valid: the conclusion of the theory must follow from its premises (HAACK 1978, 252). Thus, the test of validity is mainly a test of logical consistency and coherence between the propositions that make up the arguments of the theory. The logical consistency and coherence between the propositions of a theory makes a theory very articulate and intelligible. The arguments for CE (A1-A4) pass the test for validity. Any individual with a mastery of the techniques of symbolic logic can transform the propositions of A1-A4 as well as P1-P3 into a well-formed logical formulae and establish their formal validity using the rules of inference such as hypothetical syllogism, modus ponens and modus tollens. However, that the arguments of a given theory are valid does not mean that all the propositions of the theory are veracious. For instance, the ๖argument, "All professors can neither read nor write. Jonathan Chimakonam is a ๘professor. Therefore, Jonathan Chimakonam can neither read nor write", is valid but none of its three propositions is veracious. 
The arguments of a plausible philosophical theory are expected to be not just valid but sound and a sound argument is a valid argument that does not contain any false proposition (HAACK 1978, 251). For instance, the argument, "All individuals with demonstrable research competence in African philosophy are experts in African philosophy. Thaddeus Metz has demonstrable research competence in African philosophy. Therefore, Thaddeus Metz is an expert in African philosophy", is both valid and sound because the propositions of the argument are logically consistent and factually true. The test of veracity is thus concerned with the truthfulness of propositions. The question is whether all the propositions of $\mathrm{CE}$ are factually true. It seems to me that some of the propositions are not.

In A1, the proposition that "ambitions of a society bear witness to the quality of knowledge they possess and the ones they pursue" is not true. The ambition of a people just as the type of knowledge they seek is often a product of their prevailing circumstance. Although the European colonialists possessed a "sophisticated quality of knowledge", their expansionist ambition was more or less propelled by the prevailing circumstances in Europe as against their possession of a "sophisticated quality of knowledge".

What is happening in many sub-Saharan African countries tends to negate the last proposition in A2. Instead of constituting the "launch-pads" for creative and innovative thinking, the unfriendly socioeconomic circumstances in sub-Sahara Africa has introduced the problem of brain drain because it makes serious commitments to creative and innovational thinking and knowledge production very difficult and unattractive. The second proposition in A3 is also contestable. Inasmuch as the creative and innovative thoughts of individuals in pristine Africa were appropriated and expressed as communal thoughts, creative and innovational individuals in different fields (such as medicine, agriculture, crafts (e.g blacksmiths), warfare, and music) were celebrated and recognized. What I call the principle of "nwata kwo cha aka" in pristine Igbo society buttresses this point. According to this principle, when a child washes his hands well, he dines with elders. Given the fact that the prevailing circumstances in pristine African societies differ from that of Europe and modern Africa as well, it will be intellectually unfair to expect that what pristine Africans consider to be a creative and innovational thought that is worth celebrating will also be consider as such by the European colonialists and that it will be adequate for modern Africa.

Additionally, whether the Western episteme is qualitatively better than an articulate African episteme is arguable but it is indisputable that the Western episteme has been better articulated than African episteme. Generally, Africa's

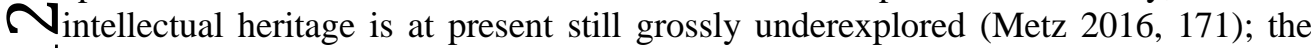
first clause of the first proposition in A4 is thus, incorrect. Finally, the claim of P1 is problematic: it is more correct to say that CE is an articulate epistemological theory ద్రా"in" (as against "for") African philosophy. 


\section{Conclusion: The Viability of $\mathrm{CE}$ as an Epistemological Theory in African Philosophy}

A sophisticated knowledge is indeed indispensable for the survival of the human species in this ephemeral world. The prevailing circumstances in postcolonial Africa are neither identical with that of pristine Africa, nor with that of Europe. Consequently, they cannot be properly addressed through the adoption of either the episteme inherent in pristine African thought, the established Western episteme, or a mere fusion of both. A plausible epistemological theory in African philosophy that can address the prevailing circumstances in postcolonial Africa and other similarly located societies can be vigorously constructed through critical study, creative adaptation and articulate reconstruction of epistemological principles inherent in both the African system of thought and the Western episteme by individual scholars who adhere to the canons of conversational philosophy. Therefore, $\mathrm{CE}$ is a viable epistemological theory in African philosophy. It can (and should) be rigorously reconceptualized and properly articulated using the canons of conversational philosophy.

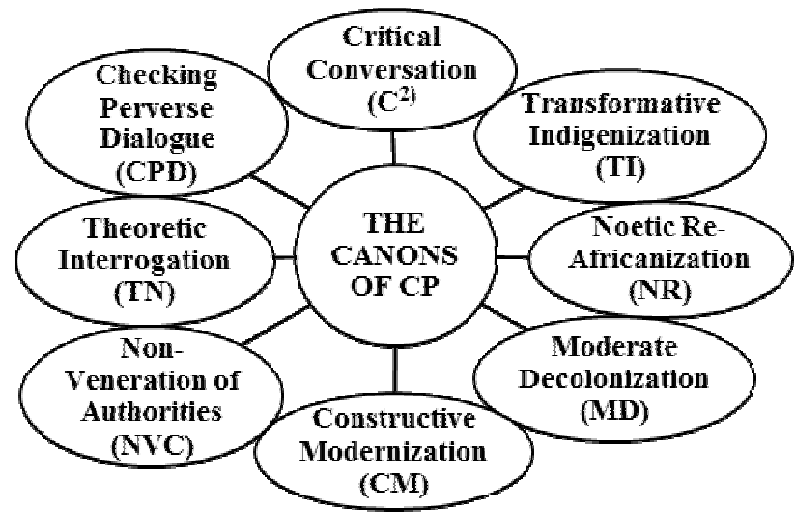

Source: NWEKE, C. A. Victor. "Complementary Reflection Vs. Binary Complementarity: An Interrogatory Discourse Of The Problem Of Anachronism In African Philosophy". Paper presented at an International Conference on African Philosophy, Past, Present and Future, Department of Philosophy, University of Witwatersrand, South Africa, Sept 9-11, 2015

According to $\mathrm{C}^{2}$, a more informed articulation of $\mathrm{CE}$ will be a product of proper conversation with existing relevant literature. Asouzu's version of "complementary Mepistemological reflection" (2004, 403-19) as well as Ozumba and Chimakonam's $\rightarrow$

${ }^{1}$ The canons of $\mathrm{CP}$ are eight interconnected criteria for doing African Philosophy as an 品academic discipline articulated by Chimakonam after a careful consideration of existing

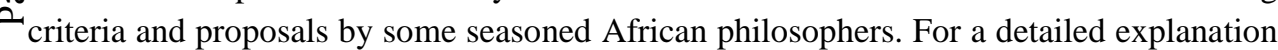
of the canons of CP see Chimakonam (2015b, 26-29) 
"Integrative epistemology" (2014) were neither mentioned nor engaged. Also the mere mention of Ijiomah's "Humanistic epistemology" (2011) is inadequate. Other works that need to be engaged, in addition to the ones consulted by Chimakonam, would include Wiredu (1980, 111-123), Anyanwu (1984), Hountondji (1995; 2004), Lauer (2002), Okere (2005: 74-83, 130 - 162), Oluwole (2014), and Chimakonam $(2015 \mathrm{c})$. I am convinced that the proper engagement of these works in the spirit of TI, NR, MD, CM, NVA, TN and CPD will improve the quality of CE as an epistemological theory in African philosophy.

However, I strongly opine that the articulate production of creative and innovational thoughts and theories in Africa (whether from the African thought or Western episteme) will only improve and be progressively sustained if the prevailing disposition of most of the governmental and non-governmental institutions; national and multi-national corporate bodies, in African countries towards the recognition and reward for intellectual ingenuity is jettisoned. At present, while most of the corporate bodies in many African countries prefer sponsoring music talent hunts and beauty pageants in order to recognize and reward outstanding artistes and beauty queens, to sponsoring academic researches (conferences) or recognize and reward outstanding scholars; academic bodies such as universities, the very ivory towers, citadels of learning and intellectual eruditions in Africa, give meaningful recognition and rewards for intellectual ingenuity based on the following criteria:

1. The Possession of a PhD: A very promising academic proposal by a scholar that does not have a $\mathrm{PhD}$ can hardly attract sponsorship. Also without the possession of a $\mathrm{PhD}$, a scholar will definitely not be promoted to the professorial cadre even when the quality of his/her publication(s) can be said to surpass the standard intellectual profundity for the outstanding academic recognition. A Professor in a reputable University in Nigeria once told a journalist: "I don't consider Achebe [referring to the revered Nigerian writer, Chinua Achebe] as a professor in the academic sense. He only has a first degree..." (Ezenwa-Ohaeto 1997: 239).

2. The Principle of Duration: A scholar with a $\mathrm{PhD}$ cannot be automatically promoted to the professorial cadre based on the outstanding quality of his/her publication(s). Such a scholar is expected to spend a specific number of years of research and teaching in a University before he/she can submit his/her publications for assessment and possible promotion to the professorial chair no matter how outstanding they may be.

3. The Phenomenon of Nepotism: An outstanding scholar with a $\mathrm{PhD}$ that possesses more than the requisite publications will find it very difficult to access research grants and can hardly be promoted to the professorial cadre even after spending the specified years if he/she does not have rapport with influential senior colleagues/members of the governing council (the elders). Conversely, any scholar that has rapport with the elders of his/her 
University will be assisted to have the minimum requirements that will take him/her to the professorial cadre at the shortest time possible. The Phenomenon of Nepotism begins with the hiring of individuals that lack the intellectual capacity, personal desire or both the intellectual capacity and personal desire to seek, generate and disseminate qualitative knowledge into the academic cadre. Hence, the paradoxical existence of many "unlearnedacademics"(Uya 2009) and "illiterate-professors" (Achebe 2003, 29-33) that are respectively teaching and "professing nothing" (Chimakonam 2015c, $25)$; miseducating and frustrating budding scholars in our institutions of learning. In sum, these three criteria are suffocating the "universe in our universities"; the very essence of scholarship - the consistent quest, generation and dissemination of qualitative knowledge in Africa, for and from Africa and beyond (Osundare 2007).

My final submission is that the inauguration of plausible creative and innovational principles and theories in African philosophy that meet the criteria of $\mathrm{CP}$ will become more pronounced when most of the necessary governmental and nongovernmental institutions; national and multi-national corporate bodies in African countries begin to recognize and reward individuals for their demonstrable intellectual ingenuity in the creative and innovational development of the African episteme in line with the principle of nwata kwo cha aka. Adhering to the principle of nwata kwo cha aka in the academic setting demands that any scholar that submits a novel academic proposal on the development of African thought for sponsorship or publish an outstanding academic work in African philosophy should be given the requisite assistance, recognition and reward such a proposal/work deserves irrespective of the academic qualification, employment status, rank, or rapport of the scholar with the influential elders in any of the institutions concerned. The aforementioned criteria should be jettisoned because they essentially kill the spirit of industrious young scholars with a knack for creative and innovative research or force such scholars to seek refuge in the Western world where the output of his/her research is properly recognized and appreciated. The time to act is now!

\section{Relevant Literature}

1. ASOUZU, I. Innocent. [The Method and Principles of Complementary in and Beyond African Philosophy], 2004. University of Calabar Press: Calabar. Paperback.

2. ACHEBE, Chinua. "Illiterate Professors and the Resurgence of Mediocrity." [Chinua Achebe Straight from the Heart: A Collection of Press Interviews, Ezenwata-Ohaeto, Ed.], Pp 29-33, 2003. Stone Press: Lagos. Paperback. 
3. ANYANWU, K. Chukwulozie. "The African World-view and Theory of Knowledge."[African Philosophy: An Introduction to the Main philosophical Trends in Contemporary Africa by E. A. Ruch and K. C. Anyanwu], Pp77-99, 1984. Catholic Book Agency: Rome. Paperback.

4. CHIMAKONAM, O. Jonathan. "The knowledge Question in African Philosophy: A Case for Cogno-Normative (Complementary) Epistemology.'[Atuolu Omalu: Some Unanswered Questions in Contemporary African Philosophy, Jonathan O. Chimakonam Ed.], Pp 67-81, 2015a. University Press of America: Lanham. Paperback.

5. __ "Conversational Philosophy as a new School of Thought in African Philosophy: a Conversation with Bruce Janz on the concept of "Philosophical Space"”. [Confluence: Journal of World Philosophies], Vol 2. No. 3, Pp 9-40, 2015b. Web.

6. __ _Building Knowledge Societies: Blueprint for Black Intellectual Revolution." [ $2^{\text {nd }}$ Distinguished CSP Scholarly Lecture Series given on Friday Nov $20^{\text {th }} 2015$ in commemoration of the UNESCO World Philosophy Day Celebration], 2015c. University of Calabar: Calabar. Lecture-Text.

7. EZENWATA-Ohaeto. [Chinua Achebe: A Biography], 1997. Oxford:James Currey. Paperback.

8. HOUNTONDJI, Pauline. "Producing Knowledge in Africa Today." [African Studies Review], Vol. 38, No.3, Pp 1-10, 1995. Web.

9. _K_ _Knowledge as a Development Issue." [A Companion to African Philosophy, Kwasi Wiredu, Ed.]. Pp 529-537, 2004. Blackwell Publishing: Malden MA. Paperback.

10. IJIOMAH, O. Chris. "Humanistic Epistemology." [Filosofia Theoretica: Journal of African Ideas and Inventions], Vol. 1, No. 1, Pp 62-78, 2011. Paperback.

11. LAUER, Helen. "Knowledge on the Cusp." [The Third Way in African Philosophy: Essays in Honour of Kwasi Wiredu, Olusegun Oladipo, Ed.], Pp171-214, 2002. Hope Publication: Ibadan. Paperback.

12. OKERE, I. Theophilus. [Philosophy, Culture and Society in African: Selected Essays by Theophilus Okere], 2005. Afro-Orbis Publications: Nsukka. Paperback 
Filosofia Theoretica: Journal of African Philosophy, Culture and Religions

13. OLUWOLE, B. Sophie. [Socrates and Orumila: Two Patron Saints of Classical Philosophy], 2014. Art Publishers: 2014.

14. OSUNDARE, Niyi. [The Universe in the University: a Scholar-Poet's Look from Inside-Out], 2007. Hope Publications: Ibadan. Paperback.

15. OZUMBA, Godfrey O. and Chimakonam, Jonathan O. [Njikoka Amaka: Further Discussions on the Philosophy of Integrative Humanism], 2014. 3rd Logic Option Publishing: London. Paperback.

16. HAACK, Susan. [Philosophy of Logics], 1978. Cambridge University Press: Cambridge. Paperback.

17. UYA, O. Edet. [Nigerian Intellectuals and the Challenges of Nation Building].April 24, 2009. University of Uyo $15^{\text {th }}$ Convocation Lecture: Uyo. Lecture-Text.

18. WIREDU, Kwasi. [Philosophy and an African Culture], 1980. Cambridge University Press: Cambridge. Paperback. 